\title{
Review of Instrument Landing System
}

\author{
Mutaz Mohammed Abdalla Eltahier ${ }^{1}$, Prof.Khalid Hamid $^{2}$ \\ ${ }^{1}$ (Department of Communication, College of Engineering/ El-neelainUniversity, Sudan) \\ ${ }_{2}^{2}$ (Department of Communication, College of Engineering / University of Science \&Technology, Sudan)
}

\begin{abstract}
This paper re-presents basic information regarding an instrument landing system (ILS),an ILS is a precision, radio navigation operates as a ground-based instrument approach system, using a combination of radio signals wherever as adopted by airports and airlines worldwide, which provides lateral and vertical guidance to an aircraft approaching and landing on a runway in weather conditions, that Otherwise might have cause in a missed approach and possible alternate to another airport, The aim of this paper is to describe and review of an instrument landing system (ILS), taken in consideration the previous studies on ILS, this paper will be as a foundation for the second paper dedicated for Evaluation of the Instrument landing system(Localizer system) used at Khartoum International Airport.
\end{abstract}

Keywords: Approach, Localizer, Glide path, Marker beacon, ILS

\section{Introduction}

An instrument approach procedure of aircrafts actually base on VHF Omni directional range (VOR), Distance Measuring Equipment (DME) and Instrument Landing System (ILS)for approach and landing, but the standard radio landing guidance system used worldwide is the ILS it was adopted by (ICAO) in 1946 as the international all-weather aircraft landing aid [1], whereas the first ILS operational use took place in 1964 [2], while the growth in air traffic has been so great, there is now at most large airports many difficulty in handling the present levels of traffic safely, especially during landing in reduced visibility or when the weather conditions are so bad, In order to overcome this problem there are many solution was advented such as the Microwave Landing System (MLS) which is a ground based system provide curving approaches, ICAO has accepted Microwave Landing System (MLS) for world-wide use [3],but it requires expensive installation in aircraft and airport and not many airports adopt to use it, Since the introduction of GPS, most existing MLS systems have been turned off in North America, FAA favoured GPS over MLS[4], The GPS is not practical in terms of accuracy and has many disadvantages that make this system not effective for use in a way that ensures the adoption of aircraft when approaching and landing on the runway without a mistake may be disastrous. Although improvements have been made in order to obtain a better resolution of this system by using differential correction messages (DGPS) and thus obtains an error ratio of 3 to 5 meters. This error may leadairplane to deviate from the runway and crash due to lack of high accuracy, and other GPS limitations are low vertical accuracy satellite transmission signal transmission time is longer than signals sent from ground surface, GPS receiverupdate rate is low, Signal degradation, ionosphere effects, and addition to the satellite unavailability whereas GPS owned by the United States Department of Defense and its availability can not be guaranteed, therefore world cannot rely on this device for navigation aid, however what's clear is that ILS can have a considerably extended era, despite the advent of the ILS is considered one of the best navigational aids invented in the history of aviation over a century ago, Therefore, improved ILS instrumentation will be of interest to the navigation Community, in addition, there are other economic benefits in equipping Passenger aircrafts with automatic landing systems which will ensure that the landing at the supposed airport will take place in intended time regardless of what's the visibility, the main purpose of this paper is to review the instrument landing system (ILS) as a system actually used on a wider scale than other automated landing systems alternative, which has not been deployed effectively yet because of their shortcomings or due to incomplete studies on development or those that still cost more than their economic feasibility and therefore the navigation Community must be focused on ILS system and try to improve it, So this paper will describe the ILS system and shows some of good aspects as well as main limitations, the paper sections gradually explained the basic ideas behind the ILS equipments, Units in ground stations ,Coverage signal and monitoring, Aircraft's On board equipment and their architecture, ILS facility Performance Categories , and some of the ILS requirement such as Accuracy/Integrity/Availability, in order tounderstand how the ILS guides the airplane down toward the runway safely, then it will shows the previous studies regarding instrument and precision landing systems with some of observations and comments and finely result and conclusion. 


\section{Purpose and function of ILS}

The approach system have a several of a technical radio devices, using for approaches and landing in reduced visibility or when the weather conditions are so bad, There are two types of approach system, precision approach which is provides both vertical and lateral guidance, and non-precision approach is which provides lateral guidance but there is no vertical guidance utility, The ILS is a precision approach system where have a main purpose within the final phase of approach to the airport it provide the pilot with information not solely on directional aircraft guidance, but also on its lateral position during, the pilot is incessantly informed on the aircraft's position related to the desired approach trajectory and therefore can perform immediate adjustments, and in other word the function of ILS is to inform the pilot of instant deviations during approach on two levels: Horizontal levelto determine whether the aircraft in the descent axis or whether it is deviating to any one side from the course, Vertical level to determine whether the aircraft is approaching the runway touchdown zone along the slope of descent or whether it is above or below the slope of descent [4].

\section{Architecture}

The instrument landing system is consisting of ground based equipment (airport ground equipment) andonboard receiving equipment (onboard aircraft's equipment).

\section{Ground basedequipments}

ILS ground basedequipmentsincludes Radio transmitters for the localizer, glide path, and marker beacons (In some cases DME system has been authorized for use when markers are not available or cannot be installed), and addition to a suitable radio navigation aid is provided to assist in interception of the localizer and holding procedures, this aid can be either a VOR or a low-powered NDB (Locator), figure.1ShowsILS diagram.

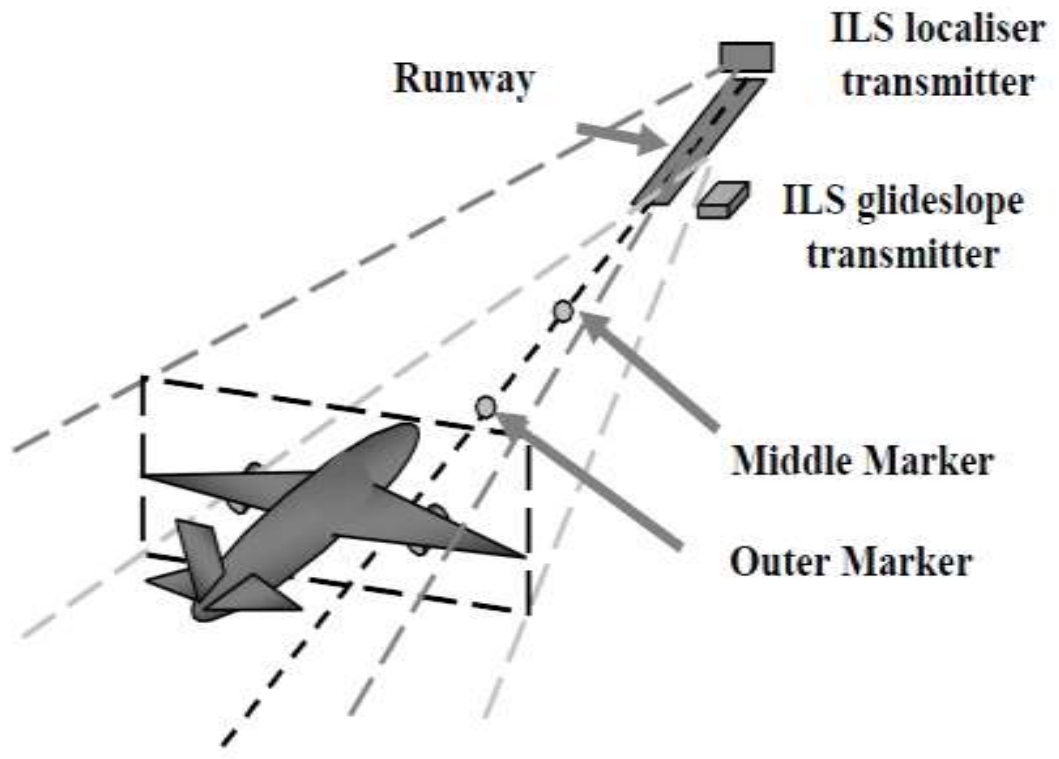

Fig.1 ILS Diagram

\subsection{Localizersystem}

The localizer transmitter radiates at a frequency in a band of 108-112 MHz, the purpose of the localizer beam is to locate the airplane on lateral trajectory so that it will intercept the centerline of the runway, this is performed by creating azimuth guidance signals that are recognized by the onboard localizer receiver [5].

The azimuth guidance signal is created by superimposing a $90 \mathrm{~Hz}$ modulated signal directed toward the left and a $150 \mathrm{~Hz}$ modulated signal directed to the right on the carrier signal. The modulation depth must be is $18-22 \%$ for ILS CAT I or II and 19-21\% for ILS CAT III , the accuracy of guidance is on the level of 15 arc minutes . figure.2shows thepattern of the localizersignal.

When the aircraft is flying straight along the projected extension of the runway centerline, both superimposed signals are detected with equal strength,however when the aircraft deviates to the right of centerline, the $150 \mathrm{~Hz}$ signal is stronger. the deviation of an aircraft from an extended runway centre line (as an angular deviation is $2.5^{\circ}$ to the right) so the receiver in the aircraft detects the difference (the vertical bar on the ILS indicator that shows the airplane to the right of the runway) and guides the pilot to fly the aircraft to the left. If the aircraft deviates to the left, the indicator will turn the bar to the left of the runway marker.

The localizer beam 'width is common $5^{\circ}$ for uncategorized systems and all other systems are adjusted to 210 meters wide at the landing threshold, Total width in terms of degrees will depend on position of localizer's 
aerials and length of runway. The localizer equipment is designed to provide a serviceable on-course signal at a minimum distance of 25 nautical miles from the runway at a minimum altitude of 2,000 $\mathrm{ft}$ above the runway threshold. Each localizer is identified audio by a coded designator consisting of three letters, the first of which is the letter 'I'. The localizer transmitters are usually duplicated, with an automatic switch changeover facility from primary to secondary equipment in the event of failure or malfunction.

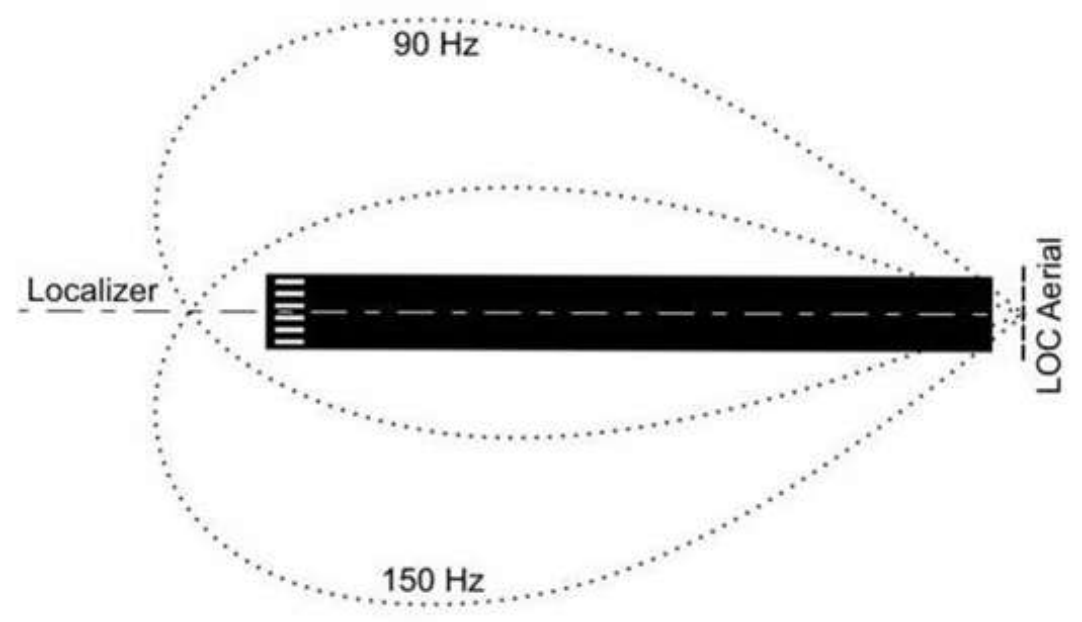

Fig.2 The pattern of the localizer signal.

\subsubsection{Coverage of signal for Localizer system}

The localizer provides course guidance throughout the descent path to the runway threshold from a distance of $18 \mathrm{NM}$ from the antenna between a height of $1000 \mathrm{ft}$ above the highest terrain along the approach path and $4500 \mathrm{ft}$ above the elevation of the antenna site. Commonly the localizer signal emitted from the transmitter site at the far end of the runway is confined within an angular width between $3^{\circ}$ and $6^{\circ}$.

Distinct off-course indications are provided throughout the areas of the operational volume these areas extend:

$\square 10^{\circ}$ either side of the course within a radius of $18 \mathrm{NM}$ from the antenna

$\square 35^{\circ}$ either side of the course within aradius of 10NM from the antenna see figure.3.

The course line along the extended centre line of a runway, in the opposite direction to the approach direction served by the ILS which is called back course.

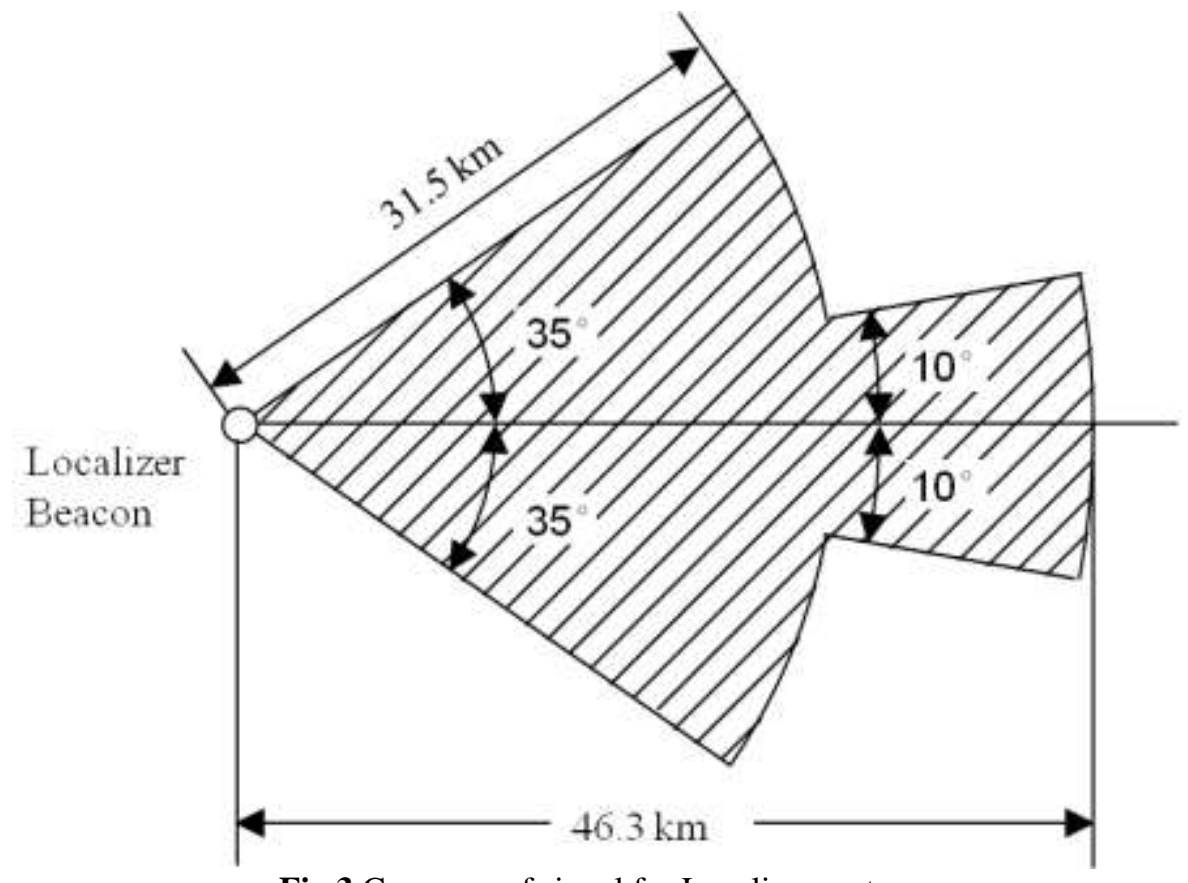

\subsection{Glide path system}

Fig.3 Coverage of signal for Localizer system 
The transmitter buildings and their antenna are located in closeness and are commonly located approximately 225-380 meters from the approach end and 120-210 meters to the side of the runway centerline, and radiates at a frequency in the range of 329.3-335.0 MHz, its purpose is to guide the aircraft down a predetermined descent path. The glide slope is normally an angle of $2.5 \sim 3^{\circ}$ to the horizontal, figure. 4 Shows a schematic of the glide path beam.

The glide path operates on a principle Very similar to the localizer, two signals are superimposed on the carrier frequency to give an error signal if the aircraft is either high or low with relative to the glide path angle, this usually is indicated by a horizontal bar on the ILS indicator that moves up or down with relevance to the glide path indicator.The glide path course is much sharper than the localizer, measuring less than $1.5^{\circ}$ from full 'fly up' to full 'fly down'.

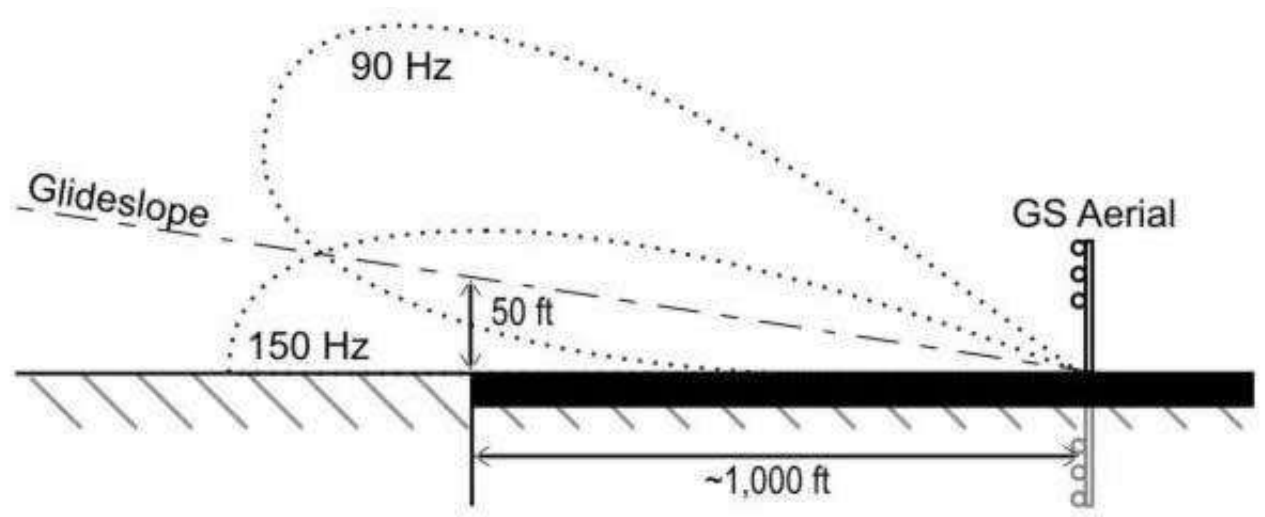

Fig.4 a schematic of the glide path beam.

\subsection{Coverage of signal for glide path system}

The glide slope is normally usable to a distance of 10NM (it can be extended when requested). The glide path provided by the glide slope transmitter is arranged so that it flares from 5 to $8 \mathrm{~m}$ ( 18 to $27 \mathrm{ft}$ ) above the runway[6], as in figures(5.1,5.2) Whereas letter $\mathrm{R}$ indicate to point at which downward extended straight portion of the glide path intersect the runway center line .

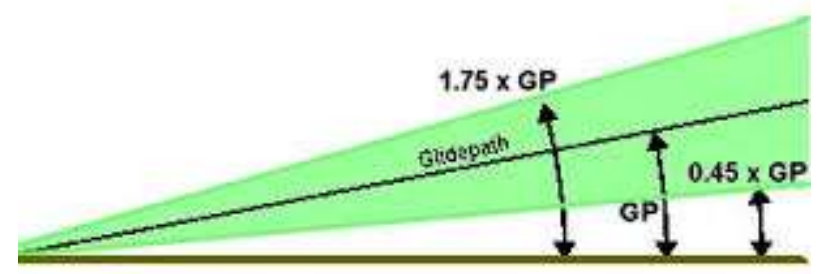

Fig.5.1. Coverage of signal for glide path system (Elevation)

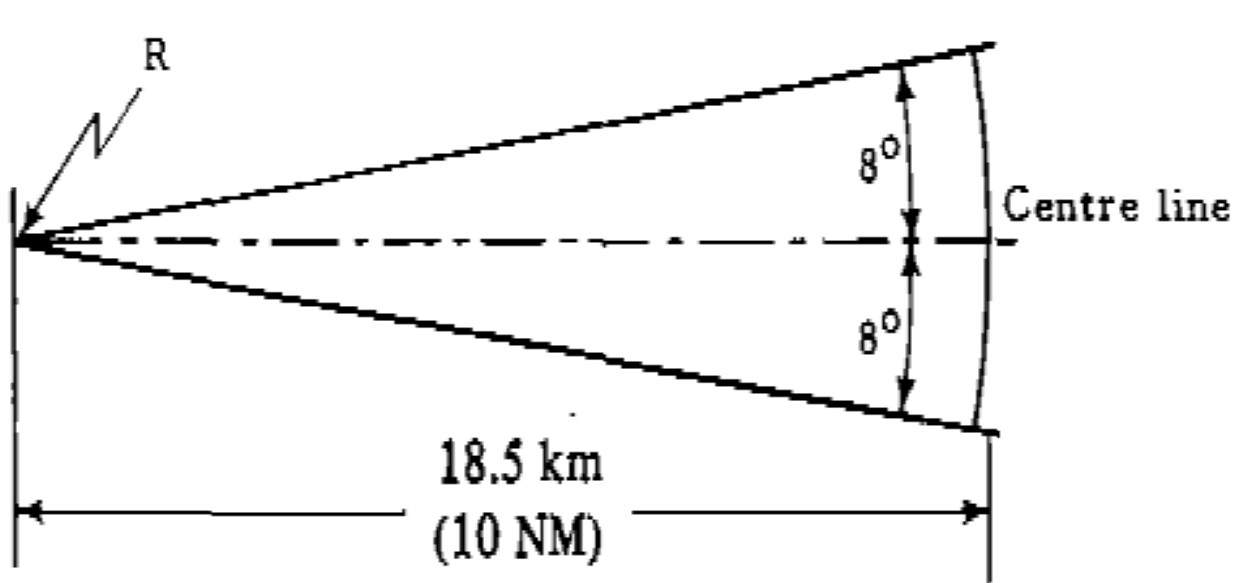

Fig.5.2.Coverage of signal for glide path system(Azimuth) 
It provide the aircraft position relative to the runway. There are three marker beacons used with ILS System, the first is located at 4 to 7 NM from the runway, is called the outer marker. the second, is middle marker is located at $3500 \mathrm{ft}(1 \mathrm{~km})$ from the runway threshold and the third is inner marker located at the beginning (threshold) of the runway.

The beams are directed vertically into the descent path at transmits of $400 \mathrm{~Hz}, 1300 \mathrm{~Hz}, 3000 \mathrm{~Hz}$ tone signals respectively on a low-powered ( 3 watts), at carrier frequency of $75 \mathrm{MHz}$. The signals are coded, and when the airplane flies overhead the signals are detected by an onboard receiver. The pilot is alerted to the passage over a marker beacon by both an audio signal and visual signal. The audio signal is heard over the aircraft's communication system and the visual signal is presented by way of a colored indicator light on the instrument panel, See figure.6.

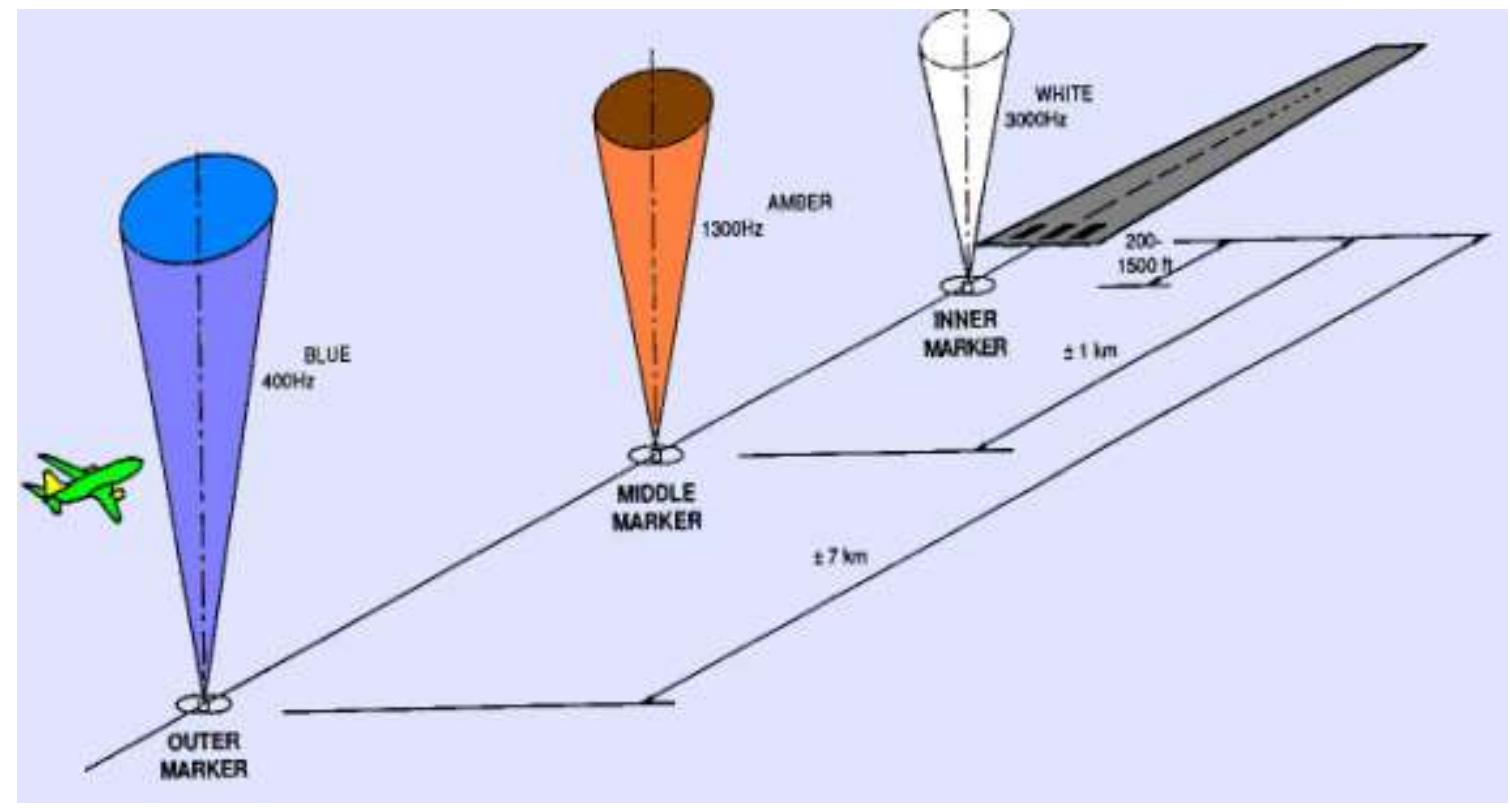

Fig.6.Marker Beacons System

\subsection{Monitoring}

To ensure safe guidance, it is essential any deficiencies of the ILS transmmitermust be detected immediately by ILS system Engineer. To achieve this, a continuous monitoring system is used to assess the vital characteristics of the transmission such as factors of accuracy for runway center line, glide angle and sector. if any significant deviation is exceeds the Allowed limits, either ILS is turned off automatically or the navigation and identification components are removed from the carrier, Otherwise will activate an indication ( The flag') on the instruments of an airplane using the ILS

\section{Onboard aircraft's equipment}

ILS equipment in an airplane contains of receivers for detecting the signals and indicators to display the information as the following:

\subsection{Localizer signal receiver}

This equipment enables to receive the localizer signal, process it and to display the aircraft's position on an onboard indicator against an axis (azimuth) and according to this to guide the aircraft into the path axis. The information provided is on the aircraft's position toward the axis position, not the path of the plane to the axis direction. In the end the displayed information on the position is similar like for example with VOR equipment (VOR enables to select the course), but it provides information on only a single specific course, that is the axis path. However, information from both systems is displayed for the pilot with the help of the same onboard equipment, only the graphic interpretation is different [7], see figure.7. 


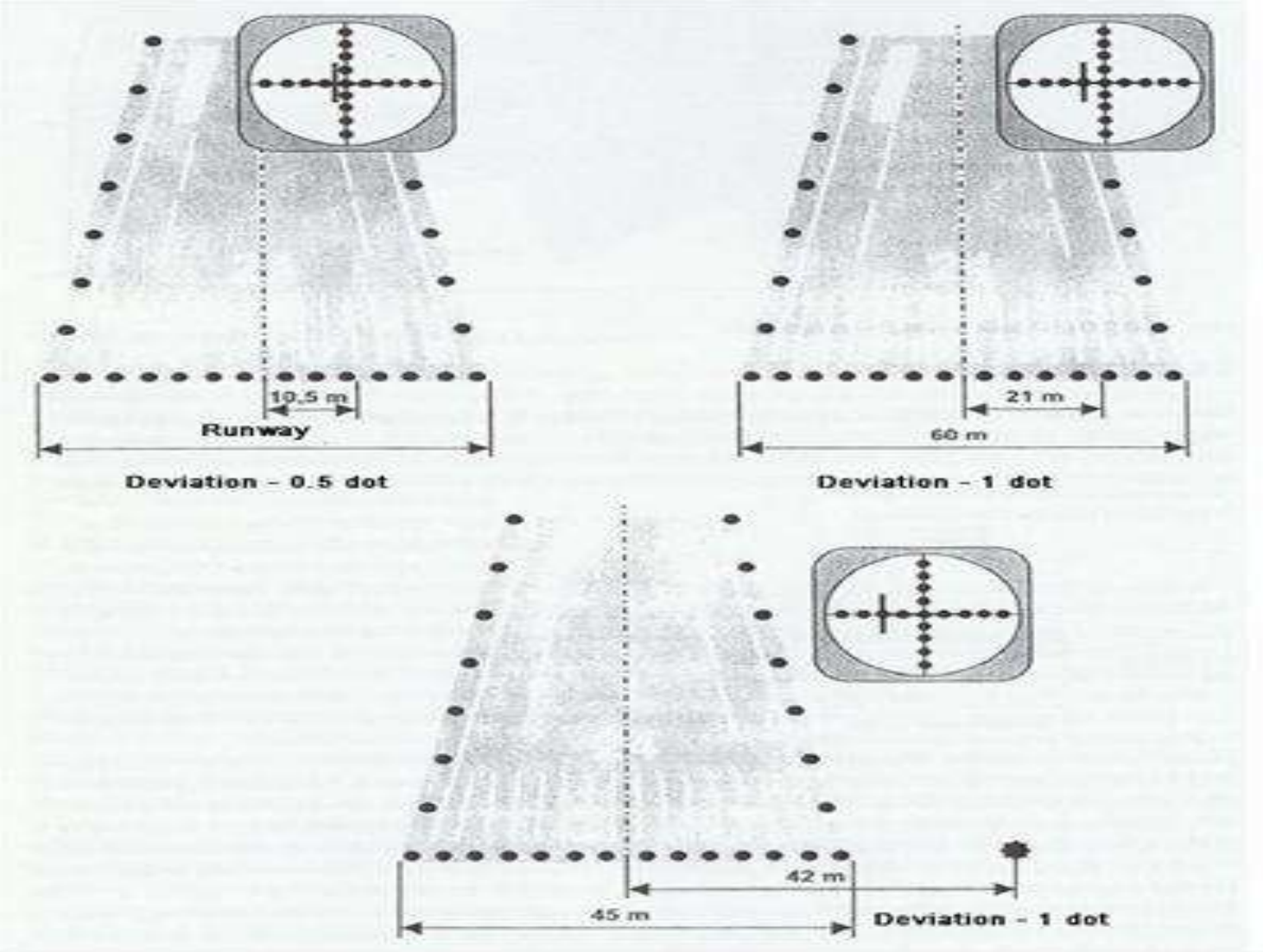

Fig.7.The deviation on Localizer signal receiver

\subsection{Glide slope signal receiver}

Similar to the localizer it receives, processes and displays the signal from the glide slope array. Glideslope path display is identical to the localizer indication. Above Outer Marker each dot means a deviation of about $500 \mathrm{ft}(150 \mathrm{~m})$ in the vertical direction from the prescribed glide-slope path. The deviation size (to a single dot) drops when approaching the runway touchdown zone - above MM is only $150 \mathrm{ft} .(45 \mathrm{~m}) /$ dot.seefigure. 8 .
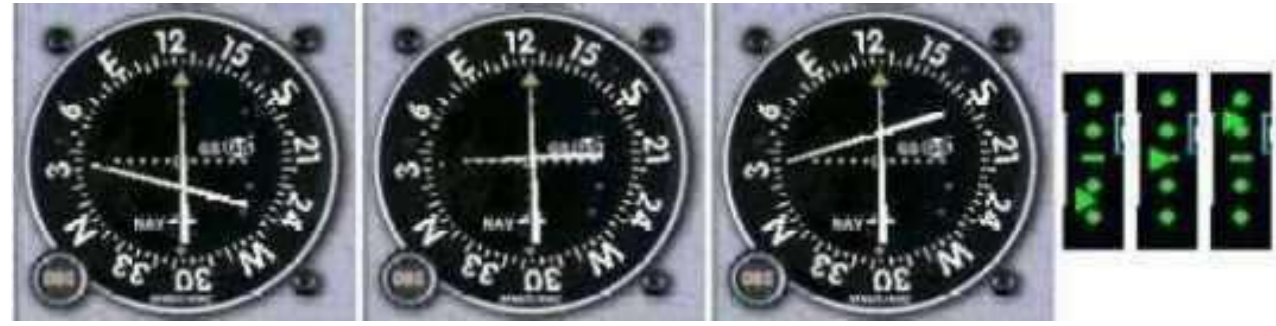

Fig.8.ILS -receiver display glide path deviation indicator

\section{ILS Categories}

The ILS ground facilities have been categorized by international standardization and ILS Categories generally characterize the ILS system preciseness and define its options for utilization according to decision height (D.H) and visibility or runway visual range(RVR) as shows in TABLE.1.

Table 1.ICAO Visibility Categories[8]

\begin{tabular}{|c|c|c|}
\hline CATEGORY & & RVR \\
\hline I & D.H & $800 \mathrm{~m}(2600 \mathrm{ft}$ \\
\hline II & $60 \mathrm{~m}(200 \mathrm{ft})$ & $400 \mathrm{~m}(1200 \mathrm{ft})$ \\
\hline IIIA & $30 \mathrm{~m}(100 \mathrm{ft})$ & $200 \mathrm{~m}(700 \mathrm{ft})$ \\
\hline IIIB & -- & $30 \mathrm{~m}(150 \mathrm{ft}$ \\
\hline IIIC & -- & Zero \\
\hline
\end{tabular}




\section{Accuracy}

\section{ILS and ICAO requirement}

ForLocalizer: The ICAO accuracy requirement for the localizer is defined by the point at which the centre of the course crosses the runway threshold and depends on the category of approach:

Cat I - within $35 \mathrm{Ft}$. This, for a $6000 \mathrm{Ft}$. runway is equivalent to $0.29^{\circ}$, Cat II - within $25 \mathrm{Ft}$. This, for a $6000 \mathrm{Ft}$. runway is equivalent to $0.2^{\circ}$, Cat III - within $10 \mathrm{Ft}$. This, for a $6000 \mathrm{Ft}$. runway is equivalent to $0.08^{\circ} \mathrm{e}$

Note: $1000 \mathrm{Ft}$. was added to runway length in these calculations because Localizer antenna array is usually about $1000 \mathrm{Ft}$. off the end of the runway.

For Glide Path: 0.056 Where is the nominal angle of the glide path. e.g. for a $3^{\circ}$ glide path, the maximum error is $3 \times 0.056=0.168^{\circ}$.

\section{Irregularities}

Because the course lines are determined mainly by the antenna patterns of the Localizer and Glide Path they are susceptible to reflections from buildings, terrain and foliage. Such reflections cause unwanted deviations ofthe course away from a straight line. These irregularities are called "structure". ICAO specifies the maximum levels for these deviations for the various sections of the approach and forthe three approach categories: The three main sections of the approach are: outside of the 4 NM point (usually the outer marker), between $4 \mathrm{NM}$ and $2500 \mathrm{Ft}$. and between $2500 \mathrm{Ft}$. and runway threshold. The tolerance decreases with decreasing distance to threshold and with higher category.

\section{Integrity}

As ICAO defines that the airborne receivermust monitor the sum of the modulation depths, and if this sum decreases below as set level, a warning indicator on the pilot's indicator must activated. Note: this also detects low RF signal levels. The ground station includes monitors which must detect out of tolerance conditions.

\section{Availability}

High rates availability are achieved by using two transmitters. If the operational transmitter fails or goes out of tolerance, the second is switched into the system. The time for switchover is a function of category with thehigher categories requiring shorter switchover times.

\section{Previous studies}

Some of the previous studies have been reviewed in TABLE.2 in order to clarify on which these studies are focused and what the topics and the results related to the instrument landing system.

\begin{tabular}{|c|c|c|c|c|}
\hline No & AUTHER/DATE & TITLE & $\begin{array}{ll}\text { TYPE } & \text { OF } \\
\text { STUDY } & \end{array}$ & CONCLUSION \\
\hline 1. & $\begin{array}{l}\text { David Gary } \\
\text { Lawrence } \\
\text { September } 1996\end{array}$ & Aircraft landing using GPS & PH.D Thesis & $\begin{array}{l}\text { The research focus on GPS application to more } \\
\text { critical regimes of flight and showing that system } \\
\text { can potentially meet even the stringent requirement } \\
\text { of cat III,and it is likely that GPSwill soon provide } \\
\text { aircrafts guidance in all phases of flight including } \\
\text { automatic landing roll-out and taxi. }\end{array}$ \\
\hline 2. & $\begin{array}{l}\text { Gómez .A. } \\
2014\end{array}$ & $\begin{array}{l}\text { Instrument Landing System } \\
\text { Lateral Beam Guidance } \\
\text { System Based on Sliding } \\
\text { Mode Control Technique }\end{array}$ & $\begin{array}{l}\text { Scientific } \\
\text { Paper }\end{array}$ & $\begin{array}{l}\text { The results showed a stable system even for low } \\
\text { altitudes and considering external disturbances. The } \\
\text { sliding mode controller is precise because it was } \\
\text { designed considering the non linearities of the plant. } \\
\text { The sliding mode control gave better results. }\end{array}$ \\
\hline 3. & $\begin{array}{l}\text { Stephanie MISSUD } \\
\text { September } 1996\end{array}$ & $\begin{array}{l}\text { Astudy of passenger Aircraft } \\
\text { Automatic } \\
\text { landingSYSTEMS }\end{array}$ & MSC Thesis & $\begin{array}{l}\text { All the results obtained from the ILS-coupled } \\
\text { systems designed for this study were found to be } \\
\text { satisfactory to provide acceptable landing } \\
\text { performance Using MLS as the path sensor also } \\
\text { produced good results, particularly for } \\
\text { curvedapproaches which could not be handled by the } \\
\text { ILS,so that the resulting response from the GPS } \\
\text { coupled system was unsatisfactory. The systemcould } \\
\text { cope with the loss of one satellite signal. }\end{array}$ \\
\hline 4. & $\begin{array}{l}\text { 1-Ahmad Abbas Al- } \\
\text { Ameen Salih, } \\
\text { 2- AmzariZhahir } \\
\text { March } 2013\end{array}$ & $\begin{array}{l}\text { Design of a High Accurate } \\
\text { Aircraft Ground-based } \\
\text { Landing System }\end{array}$ & $\begin{array}{l}\text { Scientifc } \\
\text { Paper }\end{array}$ & $\begin{array}{l}\text { In this paper, a ground-based positioning stations } \\
\text { based on concept of trilateration has been designed } \\
\text { in order to reduce or even to eliminate landing } \\
\text { systems errors and to achieve higher accuracy for } \\
\text { landing of aircraft can meet CAT III C. system } \\
\text { specifications have been calculated, designed } \\
\text { simulated and performed using Matlab Simulink to } \\
\text { simulate transmission and reception of data for }\end{array}$ \\
\hline
\end{tabular}




\begin{tabular}{|c|c|c|c|c|}
\hline & & & & $\begin{array}{l}\text { accurate aircraft positioning and precise guidance to } \\
\text { runway touch point.Positioning error sources have } \\
\text { been considered and eliminated providing all } \\
\text { weathers high accurate aircraft landing system. The } \\
\text { aircraft positioning simulations have been performed } \\
\text { comparing the system accuracy with current aircraft } \\
\text { landing systems. Results achieved showed that, this } \\
\text { system is far outperforming other systems. This } \\
\text { system is } 50 \text { times more accurate than GPS and } 15 \\
\text { times more accurate than DGPS,Some of GPS and } \\
\text { DGPS accuracy reduction factors have been } \\
\text { eliminated and others have been reduced resulting a } \\
\text { high accurate all-weather system capable to achieve } \\
\text { ICAO recommended standards for CAT III C to } \\
\text { enhance aircrafts toland blindly. }\end{array}$ \\
\hline 5. & $\begin{array}{l}\text { Ettore De Lellis } \\
\text { November } 2011\end{array}$ & $\begin{array}{l}\text { Autonomous Approach and } \\
\text { Landing Algorithms for } \\
\text { Unmanned Aerial Vehicles }\end{array}$ & PH.D Thesis & $\begin{array}{l}\text { this thesis presented some innovative algorithms } \\
\text { related to the autonomous approach and landing } \\
\text { system. Here "autonomy" refers tothe absence of } \\
\text { human intervention, and "unstructured environment" } \\
\text { is associated with uncertainty both in the outside } \\
\text { world (meteorological conditions, air traffic, fixed } \\
\text { and moving obstacles) and in the vehicle subsystems } \\
\text { (failures), In particular, the thesis has dealt with the } \\
\text { guidance problem of an autolandingmanoeuvre } \\
\text { taking into account all the different flight phases and } \\
\text { segments involving the management of verydifferent } \\
\text { flight envelopes and aerodynamic configurations } \\
\text { during the same mission. }\end{array}$ \\
\hline
\end{tabular}

\section{Observations and comments}

Most of the previous studies dealt with the presentation and description of the Instrument landing system as a ground system used in airports to achieve safety during landing of aircrafts on the runway, some studies dealt with the Automated landing system in side of Aircraft but some studies compared the ILS system with other system such as MLS, GPS and DGPS and the result confirm that other systems except ILS still needs more of studies and application to avoid their shortcoming while Others have addressed some of the problems related to the ILS system such as the sensitivity of their transmitter signals relative to the terrain surface and critical area, which is also an obstacle to aircraft's movement on the sides of the runway, so Installation of an ILS can be costly because of siting criteria and the complexity of the antenna, where some provided solutions and alternatives, in order to fix it, but there are essential issues that have been less in researches such as the availability and stability of the system they needs more studies for system improvement.

\section{Conclusion}

AlthoughILS system was considered the standard precision approach used in the context of various weather conditions. it seems that ILS will be in operational use for the foreseeable future, Through a review of the previous studies, it became clear that the system needs to be more efficient tomatch the safety requirements and ICAO specifications, despiteongoing improvements in the design and technological advances, the ILS system still unstable in service delivery, and it needs continuous calibration due to its signals sensitivity that are affected by several factors around it. Therefore, ILS needs continuous improvements.

\section{References}

[1]. M. Kayton, Navigation: Land, Sea, Air \& Space, IEEE press, 1990

[2]. Wikipedia, Autoland, available at : https://en.wikipedia.org/wiki/Instrument_landing_system\#cite_note16 .

[3]. L. Chittaro and S. Burigat, 3D location-pointing as a navigation aid in Virtual Environments, in Proceedings of the working conference on advanced visual interfaces, 2004, pp. 267-274

[4]. S. Snyder, B. Schipper, L. Vallot, N. Parker, and C. Spitzer, Differential GPS/inertial navigation approach/landing flight test Results, Aerospace and Electronic Systems Magazine, IEEE, vol.7,no. 5, pp. 3-11, 1992.

[5]. Pavle Boskoski1, Biljana Mileva2, Stojche Deskoski3, Auto landing using fuzzy logic , proc .6th International PhD Workshop on Systems and Control, October 4-8, 2005 Izola, Slovenia.

[6]. Training Documentation Manager ErwanL'hotellier,"navigation instrument - ILS",IVAO HQ training department,Version 2.0, Page323 February 2016 .

[7]. MarkétaČapková, ILS-Instrument landing system ground-based instrument approach system, University of Pardubice, Jana Perner Transport Faculty,Department of technology and control, Students 95,53210 Pardubice, E-mail: capkova_cz@hotmail.com

[8]. CAA-New Zealand, Instrument Procedure Design,Advisory Circular - AC173-1 Rev 0,Published by Civil Aviation Authority PO Box 3555 Wellington 6140, Aug 31, 2012. 